\title{
Sven Wernström
}

The We Fix It books by Stig Ahl (five books, 1959-1964) are little known today, but to me they were important back in the 1970s. In some ways these books are similar to Enid Blyton's Fabulous Five or Astrid Lindgren's Bill Bergson books. Like these, the action is focused on a teen gang of friends who solve mysteries and crimes. But the We Fix It gang is older and all-male, and these teenage boys are considerably more work-oriented than Blyton's and Lindgren's crime busters!

Work, indeed! "We Fix It" is really the story about a group of young entrepreneurs who perform various service functions, do odd jobs, and happen to stumble over mysteries and foul play. Tommy, Hammy, Leffe, and Kurre create their own exciting niche on the job market without having to take the (potentially everlasting) detour over the unemployment office. And into the bargain they get to solve crimes! This may sound like a strange recipe for success, but to me the We Fix It firm was more enticing than the inevitable crimesolving. I was not alone in thinking like this. One of my friends actually started his own fairly successful version of We Fix It, and I helped out when I could. It was an important experience.

When I read the We Fix It books back then, I had no clue that Sven Wernström was one of the authors behind the pseudonym "Stig Ahl" (the second author was Stig Malmberg). But if I had known, my respect for the author would have increased further. On my bookshelf, I already had many of the books in the "Flight Comrades" series (hand me downs from my dad), but also more recent Wernström books, such as the books in The Thralls series and Journey on an Unknown Planet. Both history and science fiction were my favorite genres.

Writing this Barnboken introduction to Sven Wernström, it strikes me that "We Fix It" could stand as a motto for Wernström's achievements.

In Wernström's books, there is a utopian optimism and undaunted belief in human potential - not least in young people's potential. It is possible to change things for the better. This essentially positive outlook can be seen both in Wernström's early genre fiction or in the later, politically outspoken books. It is true that the later Wernström is deeply critical of (capitalist) society, but it is a constructive criticism, not a destructive cynicism. When human

(C) 2012 Björn Sundmark. This is an Open Access article distributed under the terms of the Creative Commons Attribution-Noncommercial 3.0 Unported License (http://creativecommons.org/licenses/by-nc/3.0/), permitting all non-commercial use, distribution, and reproduction in any medium, provided the original work is properly cited. 
beings show solidarity and use technology and knowledge to make the world a better place, well, then "we can fix it."

One can also highlight the "we." In Wernström's books, there is almost always a "we": a thralls-we, a flight comrades-we, and, obviously, a "we fix it"-we. The group is in focus, not the single person; the stories are about collectives not individuals. In this case, too, I would argue that this "we" is present in both the older and newer books. It is also worth noting in this context that Wernström's own writing has surprisingly often been a collective undertaking. "Stig Ahl" is such a "we." But Wernström also wrote nine girls' books under the collective pseudonyms "Siv Malmström" and "Sonja Berg" (these also co-written with Stig Malmberg).

Finally, a "we fix it" attitude pervades Wernström's entire oeuvre. In it, we find typical boys' and girls' books, adventure stories, animal books, and ghost stories. You can find historical adventure stories, science fiction, detective stories, and travel accounts. Some of it is written to entertain, some of it to raise political awareness. His collected works (ca. 80 books) do not contain everything - yet! - but it certainly covers a great deal. (And if one were to ask for a specific genre, I am sure he could fix that too!)

His fix it attitude to writing is liberating. Writing is work, a craft, and in his approach there is little room for romanticized ideas about inspiration and genius. Seeing such no-nonsense attitude to writing, I find it easier to get down to business myself. In Wernström's case, this writing method has led to an impressive lifework quantitatively, but also, I would argue, in terms of quality. For even when it comes to writing, quality is often a result of quantity. Simply put: in order to become a good writer, you need to write a lot.

In this issue of Barnboken, we scrape the surface of Wernström's work. Jerry Määttä deals with Wernström's science fiction, mainly the early Flight Comrades books, but he also assesses Wernström's later contributions to the genre. Among other things, Määttä shows the role Wernström played in establishing the science fiction genre in Sweden from the 1940s and onwards.

Olga Holownia provides an analysis of the reception of Wernström on Iceland. The focus in her article is on Wernström's controversial portrayal of Jesus in Kamrat Jesus [Comrade Jesus]. Even if there were also critical voices in Sweden on the publication of this book, it appears to have been mild in comparison to the uproar caused by the Icelandic Félagi Jésus.

Another controversy is focused in Tommy Gustafsson's contribution, specifically the censoring in Swedish TV of some scenes in the 
Danish TV production of The Thralls. Gustafsson's media analysis also provides the basis for a comparison between the political and aesthetic radicalism of the 1970s compared to the prevalent conservative discourse of earlier and later decades.

Finally, Maria Andersson writes about Wernström's recontextualization of The Wonderful Adventures of Nils by Selma Lagerlöf in his own work, Den underbara resan [The Wonderful Journey]. How does Wernström write the nation? In what ways does he make use of the older, canonical text?

This issue of Barnboken does not "fix it all" when it comes to Wernström's rich and many-faceted production. There remains much to be done, both with regard to separate books (and series of books) and concerning Wernström's lifework. There are things to be done, mysteries to be solved.

They would have liked that - Tommy, Hammy, Leffe, Kurre and the rest of them!

Björn Sundmark 